\title{
Role of Information Technologies in Electronic Information Transfer and in Providing Value-added Information Services
}

\author{
V Sreenivasulu
}

\begin{abstract}
Information technology plays an important role in electronic message transfer, electronic data interchange (EDI), electronic files transfer protocols, transfer of voice, text and images through ISDN, remote electronic information access and retrieval, and the enforcement of research, education and distance learning through 'virtual global university'. In future, these information technologies can engage in interactive TV, picture phones and TV/PCs purchase. Findings of a survey, conducted to determine the potential. use, non-use and non-availability of IT service in different libraries/documentation centres are also given.
\end{abstract}

\section{INTRODUCTION}

The spectrum of information technology (IT), includes devices and strategies running from computers to communications, from video games to virtual reality, from desktop publishing to digital photography and from highend to high definition TV. Information technology may be called as the mother of technologies. IT has created or made possible the availability of awesome quantities of information. IT provides a number of value added information services and facilitates electronic information transfer.

\section{ELECTRONIC INFORMATION TRANSFER}

Information and communication technologies, electronic devices and systems enable computers and people to be connected in order to share information resources. These technologies facilitate transfer of electronic data or information from one place to another, one person to another and from traditional library to the universal library-a vast distributed information and active advice repositoryaccessible from anywhere with increasingly improved indexing, extortion, retrieval, and data mining techniques. It will be a library without walls such as internet-based world wide web.

\subsection{Electronic Message Transfer}

The most common example of this technology is electronic mail. The objective of electronic messaging technology is to allow the efficient transfer of messages of all kinds between the users of networks. Voice mail is also a form of electronic messaging. Internet mail supports transfer of text files only and multimedia internet mail system (MIMS) use still animated video images, graphics and text to pass messages. Internet mail and MIMS are yet to be adapted widely.

\subsection{Electronic Data Interchange}

Electronic data interchange (EDI) is the direct computer-to-computer exchange of electronic information. While this is a general definition, EDI is really focused on transfer of 
electronic information normally provided in digital documents. The benefits of using EDI over traditional mechanisms include cost saving, speed, error reduction and security.

\subsection{Electronic File Transfer through Protocols}

If the user wishes to acquire a specific or complete information from a digital source then file transfer operation is usually preferred. Electronic file transfer allows pieces of information to be transferred that may not exist in print or other traditional media. File transfer mechanism enables efficient transfer of both text and non-text characters. Thus, information transfer can take place completely and efficiently. Commonly used protocols are FTP, TCP/IP for internet, and file transfer access and management (FTAM) for OSI-based information systems. TCP/IP protocol is well suited protocol for data transfer and communications.

\subsection{Remote Electronic Information Access and Retrieval}

Remote electronic access is user's ability to make use of an information provider's services at a distance. It enables information to economise their operations without eliminating access for distant users. Thus, a large number of users can be served without extensive need to travel.

While remote access technology requires information specialist training. Electronic remote access requires user training, computer professionals and also user's data terminals for connection via a modem and telephone lines or data networks. Electronic remote access also implies a reliable, high-quality telecommunication infrastructure.

\subsection{Digital Convergence and Connectivity}

Digital convergence is the technological merger of several technologies in the form of various devices for exchanging information in the electronic, or digital format used by the computers. The industries are computers, communications, consumer electronics, entertainment and mass media.
Wired or wireless communications links offer several options for information and communication. The ability to connect communication devices by telecommunications lines to other devices and sources of information, known as connectivity, provides number of services such as telephone related services-fax, voice mail, e-mail, teleconferencing, video conferencing, resource sharing, electronic data exchange, online information services for research, e-mail, games, electronic bulletin boards .services (BBSs), global Internet for information gathering, discussion and new groups. In future, these technologies can engage in interactive TV or video through set-top boxes, picture phones and TV/PCs.

\subsection{ISDN}

ISDN is a set of international communication standards for transmitting voice, video, text, images and data simultaneously as digital signals over twisted-pair telephone lines. The main benefit of ISDN is speed. It allows people to send digital data ten times faster than the modern modems deliver on the analog voice network.

\subsection{Virtual Global University}

By using IT like video networks or virtual classrooms the distance learning would replace lecture halls and scheduled class time-tables. Students can take video field trips to distant places and get information from remote information centres and libraries. Information technologies link information providers and researchers.

\section{USE OF IT IN LEADING INDIAN LIBRARIES}

A survey to determine the potential use, non-use of information technology by users and library professionals to solicit their opinions, and to know the availability of each information technolagy services/facility in their libraries documentation centres (including DESIDOC, INSDOC, NASSDOC, National Council of Applied Economic Research, American Center Library and British Council Library) was conducted. The objective of this survey was to 
understand the use, non-use and non-availability of IT with reference to important Indian libraries using modern technology. Seventy questionnaires were distributed and the response through 54 questionnaires was received back. Figure $A$ and $B$ represent the results of the survey

\section{Use of IT/Services (in Per cent)}

CD-ROMs, Laser disc, video disc

Fax or Telex

Internet/Networks

E-mail

Online

Multimedia/Hypertext

Non-use

Motion Pictures, films

Computer Cassettes/Cartridges

Audio tapes/cassettes

60

Electronic BBS

60

Electronic Newspapers

56

Video, Videotapes

56

50

Non-availability of IT/Services

Teleconferencing

78

Video Conferencing

76

Video Telephony

ISDN
DTP/Electronic Publishing

Pagers, Cellular Phones

\begin{tabular}{ll}
\hline Use of Software & $\%$ \\
Windows & 96 \\
Wordstar & 94 \\
dBase/Foxpro & 68 \\
Lotus 123/Spread Sheets & 60 \\
Word Perfect & 60 \\
Non-use & \\
LIBSYS & 50 \\
MINISIS & 50 \\
SUCHIKA & 46 \\
CDS/ISIS & 44 \\
\hline
\end{tabular}

\section{CONCLUSION}

The transfer and diffusion of electronic information in providing value added information services is central to the success of the information technologists, computer engineers and software specialists. Better understanding the generation, transfer, diffusion and use of electronic information is an important component of the strategies used by IT industry would contribute to increase the productivity, stimulating innovation, and improving the professional competence of

Figure A: Potential use, nonuse and nonavailability information technologies by users and library personnel

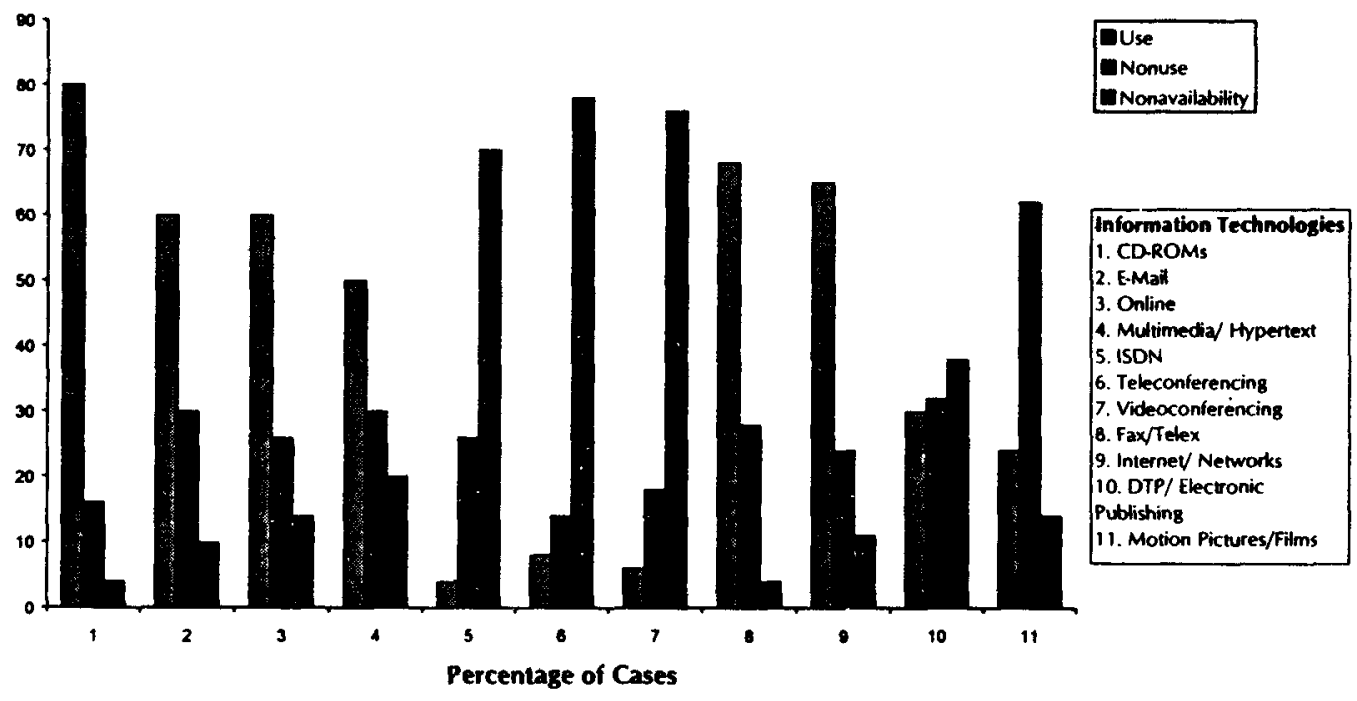


Figure B: Comparison among high potential use, nonuse and nonavailability of information technologies/ services

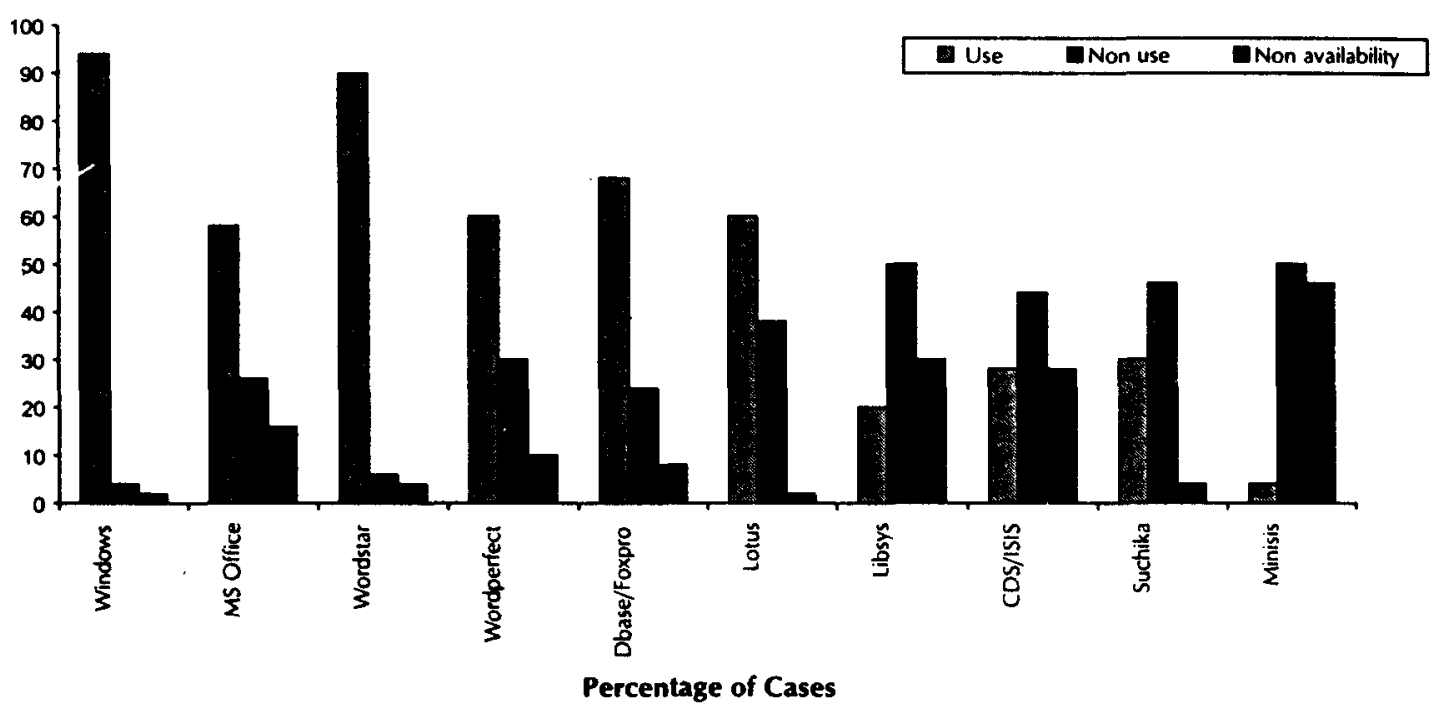

users, and library professionals in libraries/information centres. In future, information technologies can engage in interactive TV, picture phones and TV/PCs.

CD-ROMs; Fax, Internet, Networks, Windows and Wordstar are mostly used by users in libraries. Computer cassettes/catridges and audio tapes are not used widely. Teleconferencing, video conferencing, video telephony and ISDN services are not available in most of the libraries.

\section{ACKNOWLEDGEMENTS}

I express my deep sense of gratitude to Director General, National Institute of
Agricultural Marketing (NIAM), Jaipur and Shri RP Meena, Director, NIAM for their acceptance to present this paper. I am thankful to Dr Khan, Consultant and Officer-in-Charge, Library, NIAM for his thoughtful comments and suggestions.

\section{FURTHER READINGS}

1. Williams, Brian K; Sawyer, Stacey C \& Hutchinson, Sarah E. Using information technology: A practical introduction to computers and communications. Irwin, Chicago, 1995.

2. World Information Report 1997/98.

Shri $V$ Sreenivasulu is information specialist at Indian National Scientific Documentation Centre (INSDOC), Delhi - 110067 